\title{
The Effect of Rainfall on Columbia Milkvetch
}

Toxicity

\author{
W. MAJAK, R. J. WILLIAMS, A. L. VAN RYSWYK, AND B. \\ M. BROOKE
}

Highlight: Daily precipitation patterns were compared to the variation in miserotoxin concentration of Columbia milkvetch (timber milkvetch) sampled sequentially during the spring and summer of 1973 and 1974. On rough fescue grasslands, the substantial increase in rainfall during the April-to-A ugust period of 1974 not only extended toxicity intervals but also increased miserotoxin levels during the prebud growth stage. A large-scale rain storm induced miserotoxin synthesis during the pod stage. Greater soil moistureholding capacity at one grassland experimental plot prevented a rapid decline in miserotoxin levels when drought conditions developed. In contrast, the toxicity trends on Douglasfir forest sites did not show a response to variations in precipitation and toxin differences between local sites were not significant. Consequently, a predictability equation was developed for Columbia milkvetch toxicity in Douglasfir forests on Gray Luvisolic soils.

Significant variations can occur in the concentration of the poisonous principle of Columbia milkvetch (Astragalus miser var. serotinus), also called timber milkvetch, as demonstrated by miserotoxin analyses in composite and individual sampling experiments on rangelands in British Columbia (Majak et al., 1974; Majak and McLean, 1975). The former study revealed toxicity patterns for grassland, semiopen areas, and montane forests during the spring and summer of 1973; the latter showed similar trends for 1974 based on the variability of individual Columbia milkvetch plants at the bud, flower, and pod stages of growth. The bud stage of Columbia milkvetch growing on grassland sites exhibited the highest toxicity, with a decline occurring in subsequent stages. Forested sites with a medium canopy revealed significantly lower concentrations over all grow th stages. The composite study revealed a number of secondary peaks in the graph of toxicity vs time, and the variability study indicated an interseasonal difference in toxicity values. As part of our program to develop reliable predictability criteria of Columbia milkvetch toxicity, experiments were conducted to determine climatic effects on miserotoxin concentration.

\footnotetext{
Majak, van Ryswyk, and Brooke are plant biochemist, pedologist, and research assistant, Research Station, Agriculture Canada, Kamloops, British Columbia; Williams is meteorologist, B.C. Environment and Land Use Committee Secretariat, Kamloops.

The research report is Contribution Number 251, Research Station, Kamloops, B.C.

The technical assistance of Miss A. Wilkinson, Mr. K. Broersma, and Miss W. Tanner is gratefully acknowledged.

Manuscript received August 12, 1975.
}

\section{Materials and Methods}

Composite sampling of Columbia milkvetch (Majak et al., 1974) was conducted at weekly intervals on four rough fescue (Festuca scabrella) grassland sites (plots 1 to 4) and three montane forest sites (plots 13, 20, and 21) near Kamloops in the spring and summer of 1974 . Vegetation classification and physical features of plots 1 to 4,13, and 20 (Watching Creek) have been described previously (Majak et al., 1974; Majak and McLean, 1975). Plot 21 (south-facing, 20\% slope; elevation $884 \mathrm{~m}$ ), on a Gray Luvisolic soil, was located in a mixed forest of aspen (Populus tremuloides), lodgepole pine (Pinus contorta), and Douglasfir (Pseudotsuga menziesii).

Columbia milkvetch moisture content was derived from the oven-dry weight determinations of fresh-frozen samples as outlined previously (Majak et al., 1974).

The amount of time required to apply Extract 1 (Majak and Bose, 1974) to Avicel TLC plates was reduced by making the layers $1 \mathrm{~mm}$ thick instead of $0.5 \mathrm{~mm}$. The colorimetric reagent, diazotized para-nitroamiline (Majak and McLean, 1975) was stable for 3 months if stored in the dark at $4{ }^{\circ} \mathrm{C}$.

Monthly meteorological summaries and surface weather charts were provided by various centers of the Atmospheric Environment Service (AES), Environment Canada. Daily rainfall for the Kamloops area was recorded at the Kamloops Airport (elevation $345 \mathrm{~m}$ ). That the precipitation patterns for Kamloops Airport were applicable to the Columbia milkvetch experimental plots was substantiated by daily climatological station reports at Heffley Creek (elevation $683 \mathrm{~m}$ ) and the Higland Valley (elevation 1,472 m) (AES, 1974a). The experimental plots (elevation 884 to $1,097 \mathrm{~m}$ ) were situated above Kamloops Airport and between the Heffley Creek and Highland Valley weather stations.

The system of the Canada Soil Survey Committee (1974) was used for soil classification. Soil organic matter was determined according to the method of Walkley-Black (Allison, 1965).

\section{Results and Discussion}

\section{Fescue Grassland}

The abbreviated Columbia milkvetch growth period on grasslands in 1973 was attributed to drought conditions (Majak et al., 1974). Conversely, the rainfall pattern during the spring and summer of 1974 (Fig. 1C) prolonged the growing season. Much less precipitation occurred during the months of April, May, June, July, and August in 1973 (percent of normal: $19 \%, 48 \%, 59 \%, 9 \%$, and $15 \%$, respectively) than in $1974(158 \%, 109 \%, 17 \%, 97 \%$, and 56\%, respectively) (AES, 1973 and 1974). Terminal miserotoxin values for 1973 (Majak 
et al., 1974) serve to accentuate the extended toxicity interval at plots 1 to 4 in 1974 (Fig. 1A). Mixerotoxin levels in 1974 were prolonged for a month at plot 1 , for 2 months at plots 2 and 3 , and for 3 months at plot 4 .

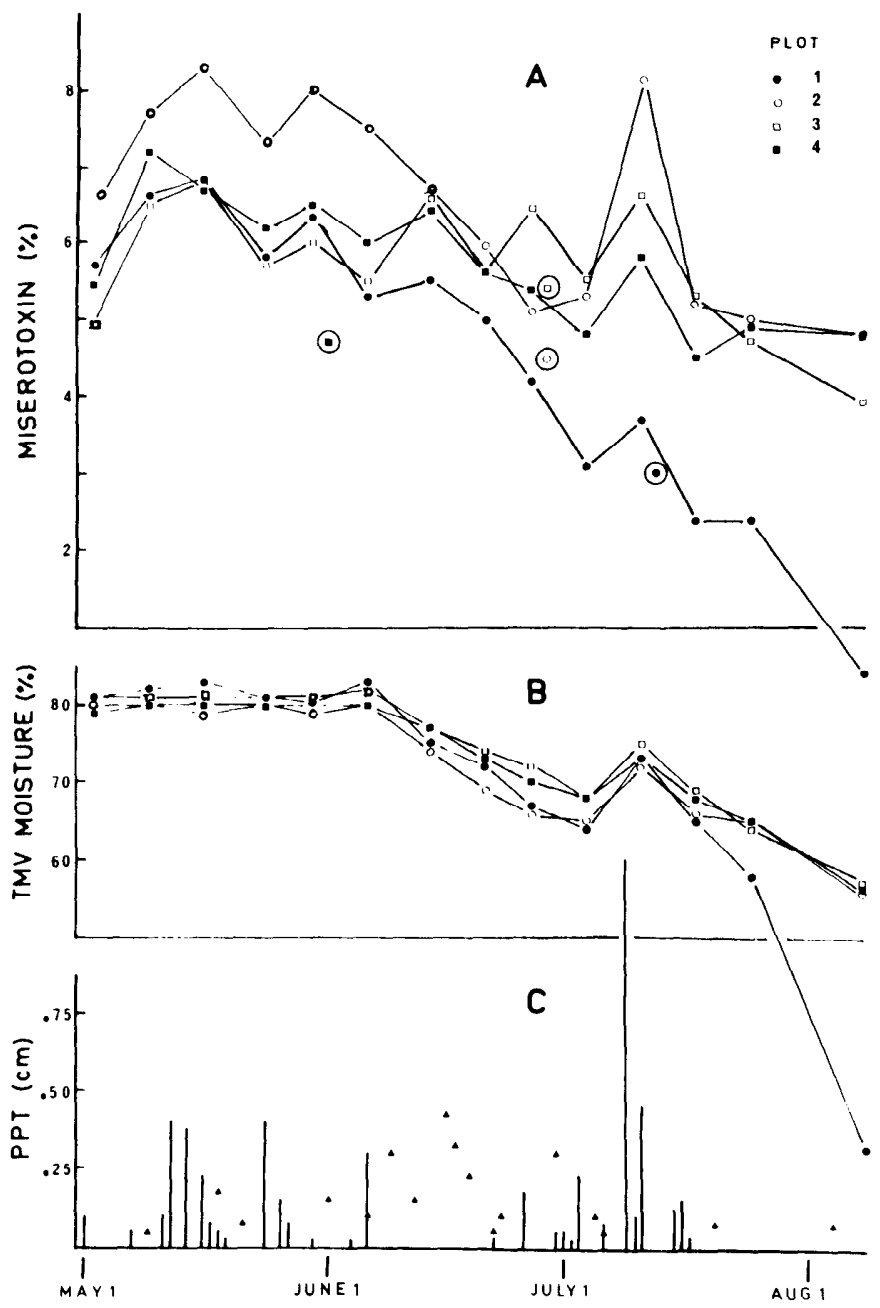

Fig. 1. (A) Weekly variation in miserotoxin concentration (percent dry weight) of Columbia milkvetch on grassland plots in 1974 with terminal values for 1973 circled. (B) Corresponding changes in moisture content of Columbia milkvetch (TMV) collected in 1974. (C) Daily precipitation (PPT) for the Kamloops area during spring and summer of 1974 (bar graph) and 1973 (triangles).

Peak miserotoxin levels (6.8 to 8.3\%) at plots 1 to 4 (Fig. $1 \mathrm{~A})$ were observed during the extended prebud phase in spite of unseasonably low temperatures in May 1974 (the second coldest May on record in Kamloops) (AES, 1973 and 1974), which delayed bud formation by 2 weeks. With the exception of the maximum for plot 3 (see below) in 1973, consistently higher miserotoxin levels were observed in 1974 than in 1973. The differences during the prebud interval could not be accounted for solely on the basis of individual variation (Majak and McLean, 1975) and therefore it was proposed that the above normal rainfall in May and July 1974 could result in significant increases in toxin levels and extensions of the period of toxicity.

The below average rainfalls in June of 1974 and 1973 resulted in substantial declines in the moisture content of Columbia milkvetch at plots 1 to 4 . Plots 1,2 , and 4 also cxhibited corresponding decreases in miserotoxin concen- tration (Fig. 1A and 1B). Observations on soil moisture content and tension at neighboring grassland reference points in 1974 revealed significant declines approaching soil moisture stress conditions in late June ${ }^{1}$; this was reflected in the soil moisture determinations at plots 1 and 4 (Table 1). Exceptional moisture conditions at plot 3 were indicated by significantly higher soil moisture (Table 1), and correspondingly higher Columbia milkvetch moisture content during the period June 14 to August 9, (Fig. 1B). The greater moisture-holding capacity of plot 3 was related to the higher soil organic matter content $(11.3 \%)$ of the deep, Orthic Black Chernozem as compared with plot 1, a thin Orthic Black Chernozem (7.6\% organic matter), plot 2, a Rego Black Chernozem (8.0\%), and plot 4, an intergrade between the Orthic Brown and Orthic Black Chernozems (7.3\%). The soil moisture-holding capacity of plot 3 appeared to prevent a rapid decline in miserotoxin levels during the month of June and similar patterns were observed at this site in 1973 (Majak et al., 1974) and 1972 (Majak and Bose, 1974).

Table 1. Changes in soil moisture (percent) ${ }^{1}$ at Columbia milkvetch experimental sites.

\begin{tabular}{|c|c|c|c|c|c|c|}
\hline \multirow{2}{*}{\multicolumn{2}{|c|}{ Date 1974}} & \multicolumn{5}{|c|}{ Plot no. } \\
\hline & & 3 & 4 & 13 & 20 & 21 \\
\hline \multirow{2}{*}{ June } & 14 & & & 19 & $28(14)$ & $14(10)$ \\
\hline & 21 & $18(15)$ & $5(5)$ & & & \\
\hline \multirow{4}{*}{ July } & 27 & & & $14(14)$ & $12(10)$ & $8(10)$ \\
\hline & 4 & $20(11)$ & $6(7)$ & & & \\
\hline & 12 & & & $27(15)$ & $25(19)$ & $24(12)$ \\
\hline & 18 & $44(21)$ & $24(14)$ & & & \\
\hline \multirow{3}{*}{ Aug. } & 25 & & & $16(14)$ & $16(11)$ & $13(12)$ \\
\hline & 9 & $10(8)$ & $4(5)$ & & & \\
\hline & 19 & & & $15(12)$ & $12(8)$ & $15(5)$ \\
\hline
\end{tabular}

${ }^{1}$ Each value is the average from three gravimetric determinations at depths of 2.5 and $20 \mathrm{~cm}$ (in parentheses). Plot 1 yielded values of 7(6) on June 21.

The Columbia milkvetch full-flower to mature-pod interval for 1974 occurred between June 21 and August 25. The most significant climatic feature for this period as compared with 1973 (AES, 1973 and 1974) was a large-scale storm system during July 9 to 11 (AES, 1974), which deposited a heavy rain $(1.27 \mathrm{~cm}$ on July 9 at Kamloops Airport) throughout the study area (Fig. 1C). Precipitation from the storm was recorded at elevations from valley bottom $(345 \mathrm{~m})$ to $1,737 \mathrm{~m}$ (AES, 1974a). The west to east passage of the storm was evidenced by heavy precipitation 2 days earlier at Highland Valley $(1.57 \mathrm{~cm}) 48 \mathrm{~km}$ southwest of Kamloops, and one day later at Salmon Arm $(1.59 \mathrm{~cm}) 80 \mathrm{~km}$ east of Kamloops (AES, 1974). Corresponding soil moisture changes were recorded at 2.5 and $20 \mathrm{~cm}$ (Table 1) and related fluctuations (not listed) were detected at $10 \mathrm{~cm}$ for the grassland sites. Moisture content of timber milkvetch samples collected immediately after the storm had increased by 6 to $9 \%$ and this response coincided with a 16 to $34 \%$ increase in miserotoxin concentration (Fig. 1A and 1B). This resurgence in Columbia milkvetch toxicity points to an induced synthesis of miserotixin in response to favorable moisture conditions. It appeared that the heavy rainfall activated miserotoxin biosynthetic pathways. Timing of sample collections was obviously critical, since the induced higher concentrations were rapidly metabolized. It is conceivable, however, that extended storm systems could prolong higher miserotoxin levels. Previously we reported (Majak and McLean, 1975) no significant difference $(P=.05$ according to

\footnotetext{
${ }^{1}$ van Ryswyk, A. L. 1975 . Unpublished results.
} 
Duncan's multiple range test) between individual Columbia milkvetch plants sampled on grasslands during the pod and flower stages. The pod stage samples, however, were collected immediately after the above weather system and the elevated values at the pod stage could also be explained on the basis of induced miserotoxin synthesis. Similar interpretations could be ascribed to the secondary peak in the toxicity pattern at plot 5 in 1973 (Majak et al., 1974).

\section{Montane Forests}

In contrast to the variations in toxicity trends on grassland sites, miserotoxin levels in Douglasfir stands (either pure or mixed with aspen and/or lodgepole pine) revealed uninterrupted, gradual declines during the growing season (Majak et al., 1974; Majak and McLean, 1975). Weckly observations on miserotoxin concentrations at forest sites (plots 13,20,21) in 1974 showed similar trends with corresponding gradual decreases in Columbia milkvetch moisture content. Although the July 9-11 rainfall affected soil moisture content at the $2.5 \mathrm{~cm}$ depth on plots 13,20 , and 21 , only plot 20 , a drainage basin, showed a corresponding increase at $20 \mathrm{~cm}$ (Table 1) and 10 $\mathrm{cm}$.

Concomitant responses in either Columbia milkvetch moisture content or miserotoxin concentration, however, were not observed following the large-scale storm in spite of the higher precipitation for July at Pass Lake $(3.56 \mathrm{~cm})$ as compared with Kamloops Airport $(2.59 \mathrm{~cm})$. Rainfall interception by the canopy and absorption by forest litter, in addition to the $\mathrm{Bt}$ horizon barrier of Gray Luvisolic soils, served to reduce effective moisture penetration.

Linear regression analysis of the 1973 and 1974 data for plots 13, 14, 20, and 21 (63 miserotoxin determinations) yielded the following expression: $y=3.99-.023 x$ (where $x$ is the time in days after May 10 and $y$ is the percent miserotoxin) with $r=0.85$ (correlation coefficient) and 0.46 (percent miserotoxin) as the standard error of the estimate.
The $r$ value indicated that 72\% of the variation was explained by the above equation (Draper and Smith, 1966). Therefore, any contribution to variation due to the four sites and two years from which the data was drawn was small compared with the variation due to the time of year and this allows one to assume toxicity is not dependent on the first two factors. Allowing this assumption, one can use the above equation to predict toxicity in other years and for other sites within Douglasfir forests on Gray Luvisolic soils. A lower $r(.58)$ and a higher standard error (1.11) obtained from linear regression analysis of the rough fescue grassland sites ( 75 miserotoxin determinations, $y=6.81-0.028 x$ ) indicated that time alone did not explain the same degree of variation in toxicity as in forest sites, and the unexplained variation is presumably the result of site and season effects (Fig. 1A and C).

\section{Literature Cited}

Allison, L. E. 1965. Methods of Soil Analysis, C. A. Black et al., Eds. p. 1372-1376. Amer. Soc. of Agron., Madison, Wisc.

Atmospheric Environment Service. 1973 and 1974. Monthly meteorological summaries at Kamloops Airport, B.C. Environment Canada, Kamloops Airport, B.C.

Atmospheric Environment Service. 1974. Surface weather charts (July $7,8,9,10$, and 11, 1974). Environment Canada, Vancouver International Airport, B.C.

Atmospheric Environment Service, 1974a. Monthly record: meteorological observations in Canada (various months). Environment Canada, Downsview, Ont.

Canada Soil Survey Committee. 1974. The system of soil survey for Canada. Information Canada, Ottawa.

Draper, N. R., and H. Smith. 1966. A pplied Regression A nalysis. p. 26. John Wiley and Sons Inc., N.Y.

Majak, W., and R. J. Bose. 1974. Chromatographic methods for the isolation of miserotoxin and for the detection of aliphatic nitro compounds. Phytochemistry 13:1005-1010.

Majak, W., A. Mclean, T. P. Pringle, and A. L. van Ryswyk. 1974. Fluctuations in miserotoxin concentrations on rangelands in British Columbia. J. Range Manage. 27:363-366.

Majak, W., and A. McLean. 1975. Variability of miserotoxin concentrations in timber milkvetch. J. Range Manage. 28:362-364. 